\title{
Hydraulic Flushing Technology and Its Practice in Outburst Coal Seam with High Gas and Low Permeability
}

\author{
Qing Ye ${ }^{1 *}$, Geoff G.X. WANG ${ }^{2}$, Zhenzhen Jia ${ }^{1}$, Yi Lu' ${ }^{1}$ and Yadong Zhang ${ }^{1}$ \\ ${ }^{1}$ School of Energy and Safety Engineering, Hunan University of Science and Technology, Xiangtan 411201, China \\ ${ }^{2}$ School of Chemical. Engineering, University of Queensland, Brisbane QLD 4072, Australia
}

Received 1 June 2015; Accepted 23 October 2015

\begin{abstract}
Hydraulic flushing technology can rapidly and effectively eliminate coal and gas outbursts and improve the permeability of a coal seam. Its effect mainly depends on the technical parameters of hydraulic flushing. To solve the problems on technical parameters that exist in the application of hydraulic flushing technology, the outburst elimination mechanism of hydraulic flushing technology was expatiated, the hydraulic flushing process was introduced, and a field test was performed on the B1 coal seam in Yi' an Coal Mine by using the pressure drop method. Moreover, the effective influence radius of hydraulic flushing measure was determined, and the technical parameters were analyzed. Finally, a series of relationships was obtained, including the relationships between hydraulic pressure and coal output, critical breaking coal pressure and firmness coefficient, flushing time and coal output, drilling hole angle and coal output, and coal output and effective influence radius. Results showed that the effective influence radius of hydraulic flushing in B1 coal seam was 9 $\mathrm{m}$, and the outburst risk of the coal within the influence region was eliminated. In addition, the time of outburst elimination was shortened and the production rate was improved. The research results could provide technical support for the optimization of the technical parameters and the test scheme of hydraulic flushing measures.
\end{abstract}

Keywords: Hydraulic flushing, Flushing mechanism, Outburst coal seam, Pressure relief and permeability improvement, Effective influence radius

\section{Introduction}

Coal and gas outburst is a violent, dynamic phenomenon that occurs during the coal mining process, causes considerable harm to society, and has a high probability of occurrence, thus seriously affecting production safety in coal mines [1] . Gas drainage is a fundamental measure for preventing and controlling coal and gas outburst, and the gas drainage effect mainly depends on two aspects [2], [3], [4],[5]. One aspect is technical and includes design parameters of drilling holes and technical indexes of gas drainage equipment; the other aspect is the property of the coal seam, mainly including permeability of the coal seam [6]. The technical aspects have been studied thoroughly and is gradually matured; therefore, the current key problem of the gas drainage is to improve the permeability of coal seams [7]. In China, minable coal seams in more than $95 \%$ high gas mines have low permeability coefficient with the value of $10^{-4}-10^{-3}$ $\mathrm{m}^{2} /\left(\mathrm{MPa}^{2} . \mathrm{d}\right)$, which makes gas drainage difficult.

When three soft and low permeability outburst coal seams undergo protective layer extraction, the protective layer can be extracted first [8]. When coal seams have no mining conditions of protective layer, regional outburst

* E-mail address: cumtyeqing@126.com ISSN: 1791-2377 @ 2015 Kavala Institute of Technology. All rights reserved. elimination measures (including hydraulic measures, mechanical measures, and blasting measures) can be adopted [9], [10], [11]. Such measures relieve gas pressure and improve coal seam permeability, thus enhancing the gas drainage effect [12]. Moreover, pressure relief can increase the coal firmness coefficient of the protected coal seam, which is beneficial for preventing and controlling coal and gas outburst accidents [9], [13]. However, the mechanical measures and blasting measures have defects, such as difficult operation, limited pressure relief range, and easy generation sparks. These defects make the application effect poor. Thus, hydraulic measures can better solve the problem of low permeability of the coal seam. Hydraulic measures mainly include the hydraulic pressing, the hydraulic cutting and the hydraulic flushing, all of which obtain relatively satisfactory results in field tests. The hydraulic pressing measures and the hydraulic cutting measures are taken mainly in front of the tunneling face or working face. Coal and gas outburst may be induced in the course of implementation. Production safety cannot be fully guaranteed, and the regional outburst elimination is hard to achieve in advance [13]. The hydraulic flushing measures take the rock roadway as the safety barrier. Coal and gas are discharged under the hydraulic role; thus, the stress of coal and rock mass around the drilling holes decreases, gas pressure is relieved, and coal seam permeability is improved [14]. The gas drainage technology can then be used to further eliminate the outburst. Therefore, the hydraulic flushing measures can enhance the gas drainage effect, 


\section{Journal of Engineering Science and Technology Review 8 (4) (2015) 118- 124}

reduce the amount of engineering required, shorten the implementation time, and safely eliminate the danger of coal and gas outbursts.

\section{Description of the Problem}

Proper hydraulic flushing parameters can enhance coal seam permeability and gas drainage effect. These parameters have important significance on the popularization and application of hydraulic flushing technology. Permeability and other parameters of various coal seams are different because of different geological conditions. Therefore, the hydraulic flushing time and the gas drainage time are different. Tectonic soft coal is developed all over the coalfields in Yi'an Coal Mine. Consequently, when hydraulic flushing measures are practiced, many problems should be considered. For example, problems during the process of hydraulic flushing include how the soft coal is destroyed, what the influence of the water jet with different pressures on the coal failure process, and what the coal failure strength criterion is. In terms of coal seam thickness, the problems are drilling angle, drilling depth, gas outburst level, determining the hydraulic pressure, flow, and time of hydraulic flushing, the influence of coal output on the pressure relief range, and the relief of the pressure of the coal around the drilling hole. The hydraulic flushing technology has been well understood. Nevertheless, analysis on proper parameters, especially the water jet pressure, is not sufficiently accurate, thereby seriously affecting the development and utilization of hydraulic flushing technology. Therefore, based on the hydraulic flushing mechanism, a field test of the hydraulic flushing in Yi'an Coal Mine was performed using the pressure-drop method. The effective influence radius and other parameters of the hydraulic flushing technology were determined and analyzed.

\section{Mechanism of Elimination Outburst by Hydraulic Flushing Technology}

Domestic and foreign scholars generally believe that ground stress, gas, and physical and mechanical properties of coal are the main factors that result in coal and gas outbursts [15]. The deformation potential energy of coal and gas expansion energy are the main impetus of coal and gas outburst. The hydraulic flushing technology utilizes the rock pillar or the coal pillar as a safety barrier. The holes are drilled into the outburst coal seam, and high-pressure water is injected into the drilling holes [16]. As drilling moves forward, gas is constantly discharged from the drilling holes. Coal, water, and gas are discharged through the hole passage, thus forming a cavity with a large diameter. Simultaneously, the coal around the hole passage moves toward the cavity, thereby resulting in coal expansion and making the top and floor move toward the cavity. Therefore, the ground stress within the influence region of the drilling hole reduces, the gas is discharged, the gas pressure of the coal seam is sufficiently relieved, and the elastic potential energy of the coal and surrounding rock and the gas expansion energy are released to improve the gas drainage effect and wetting coal [17]. Wetting coal can reduce coal brittle, increase coal plasticity, and reduce coal elastic potential energy. Moreover, wetting coal can reduce gas desorption velocity and decrease gas expansion energy [11], [18], [19]. In terms of gas movement, a large amount of gas is discharged during hydraulic flushing. After the hydraulic flushing measures are finished, the influence region of the drilling hole extends gradually because of coal expansion. Coal porosity and the permeability of the coal seam increase, thereby causing distant gas from the drilling hole to be emitted into the hole passage [20]. Consequently, the main impetus of coal and gas outburst is eliminated and the physical properties of outburst coal seam are changed, which can prevent and control the coal and gas outburst in the coal mining process.

\section{System and Process of Hydraulic Flushing}

\subsection{Hydraulic flushing system}

The hydraulic flushing system consists of an emulsion pump, a water tank, pressure gauges, blowout preventers, nozzles, and etc, as shown in Figure 1. According to the situation of the field test, the BRW200/315 type emulsion pump is selected, of which the rated flow is $200 \mathrm{~L} / \mathrm{min}$ and the rated pressure is $31.5 \mathrm{MPa}$. The FRX1000 type auxiliary emulsion box is selected, of which the nominal pressure is $31.5 \mathrm{MPa}$, the volume is $1000 \mathrm{~L}$, the size is $2450 \mathrm{~mm} \times 1050$ $\mathrm{mm} \times 1400 \mathrm{~mm}$, and the weight is $700 \mathrm{~kg}$. The nozzles are PZCKC series. The SGS-type double function high-pressure water gauge is selected, and its pressure range is $0-25 \mathrm{MPa}$. SGS-type double function high-pressure water gauge connects the QJ16 type spherical cut-off valve. The type of the drilling rig is 5S-1900; the internal diameter of the high pressure hose is $32 \mathrm{~mm}$, and its compression resistance is 32 $\mathrm{MPa}$. Quick connectors and U-type clips are used at the joints. During hydraulic flushing, the gas concentration at every drilling field is recorded by the TWY type outburst predictor.

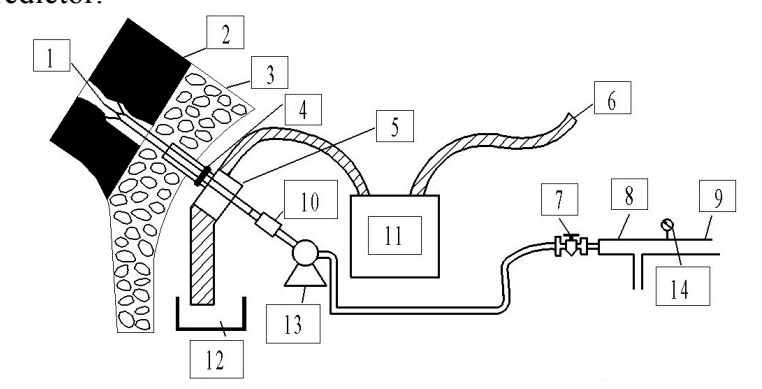

1-nozzle, 2-coal seam, 3-rock stratum at floor, 4-sealing tube, 5-blowout preventer, 6-connect gas drainage pipe, 7-cut-off value, 8 -supply pipe, 9-connect pumping station, 10-hydraulic monitor joint, 11-water-gas separation device, 12-sedimentaion tank, 13-drilling rig, 14-pressure gauge

Fig. 1. Diagram of hydraulic flushing system

\subsection{Hydraulic flushing process}

After the coal seam is drilled through, the drill rod is withdrawn, and the drilling bit is replaced by a special bit with a nozzle. The original drill rod is replaced by a drill rod with a smaller diameter (which is conducive to discharging crushed coal). The new drill rod is placed at the junction of the coal and the rock again, and the water injection pump is opened. Meanwhile, the drilling rig is opened for the drill rod to be slowly carried into the drilling hole. When the drill rod reaches the maximum depth, the flushing is ongoing as the drill rod is withdrawn; this process is repeated until no coal can be taken out and the return water is clear. The other drill rods are increased individually. Thus, the drill rod and the flushing process are repeated according to the abovementioned method until all the coals are flushed. In the 
process of hydraulic flushing, the drilling velocity is kept constant to discharge crushed coal.

In the hydraulic flushing process, high-pressure water passes through the drill rod, squirts from the nozzle on the drilling bit, and flushes the coal around the drilling bit. The drilling rig moves ahead and breaks coal, which induces small coal and gas outburst (spray orifice). Water, coal, and gas flow into the coal-water conveying system along the space between the drill rod and drilling hole. The mixture of gas and water enters the water-gas separation device. After separation, gas enters gas drainage pipes, and coal and water flow into the sedimentation tank.

\section{Test of Effective Influence Radius of Hydraulic Flushing}

\subsection{General situation of the mine}

Yi'an Coal Mine is in the middle of Zhengcun coalfield, which is approximately $6.3 \mathrm{~km}$ long on the strike, approximately $5.5 \mathrm{~km}$ wide on the tendency, and has an approximate area of $28.744 \mathrm{~km}^{2}$. The coal-bearing stratum belongs to the Permo-Carboniferous System; only B1 coal seam and B2 coal seams in Shanxi Formation are workable coal seams. Among them, the local area of B2 coal seam is workable, and the entire area of B1 coal seam is workable and is a main workable coal seam. The average thickness of B1 coal seam is $4.5 \mathrm{~m}$, the gas content is $12.61 \mathrm{~m}^{3} / \mathrm{t}$, the gas pressure is $1.37 \mathrm{MPa}$, the initial velocity of gas diffusion is $19.2-28.5 \mathrm{mmHg}$, the permeability coefficient is $0.175-$ $0.8380 \mathrm{~m}^{2} /\left(\mathrm{MPa}^{2} . \mathrm{d}\right)$, the gas flow attenuation coefficient in the $100 \mathrm{~m}$ drilling hole is $0.0253-0.0425 \mathrm{~d}^{-1}$, the firmness coefficient $\mathrm{f}$ is $0.21-0.27$, and the coal destruction types belong to IV and V. In addition, B1 coal seam has a tendency of coal and gas outburst. The development of the coal seam in Yi'an Coal Mine is complete, the thickness is large, the destruction is serious, the existing gas prevention and control technology and equipment cannot satisfy production safety requirements, as mainly manifested by the poor permeability and softness of the coal seam and predrainage difficulties of the existing gas drainage technology. Consequently, a hydraulic flushing test is conducted. The test place is in the floor roadway of the FD003 working face in Yi'an Coal Mine. The design length of the working face is $135 \mathrm{~m}$, the design length of the track crossheading is $773 \mathrm{~m}$, and the design length of the belt crossheading is $812 \mathrm{~m}$.

\subsection{Test method of effective influence radius of hydraulic flushing}

The common test methods for determining the effective influence radius of the hydraulic flushing are the flow method and pressure drop method. When the flow method is used, improper selection of measurement range may easily cause a reading error, which will affect the test results [12]. When the pressure drop method is used, the influence range of high-pressure water jet can be observed directly. Therefore, the pressure drop method is used in this test. The principle of the pressure drop method is as follows: In the hydraulic flushing process, the cracks in coal affected by water jet extend, the gas pressure in the coal seam drops, and the pressure in drilling holes can be used to directly determine the position affected by the hydraulic flushing measures.

According to the test specification[21], [22], when the gas pressure in the drilling hole drops to $0 \mathrm{MPa}$, the distance $R \mathrm{i}$ from the drilling hole to its corresponding measure hole is within its effective influence radius. Among them, the maximum distance $R_{\max }=\operatorname{Max}\left(R_{1}, R_{2} \ldots R_{\mathrm{n}}\right)$ is the effective influence radius of the hydraulic flushing measures.

\subsection{Test steps}

The test is performed in the stable region of the belt crossheading of the FD003 working face in Yi'an Coal Mine. The layout of the drilling holes is shown in Figure 2, and their layout parameters are shown in Table 1.

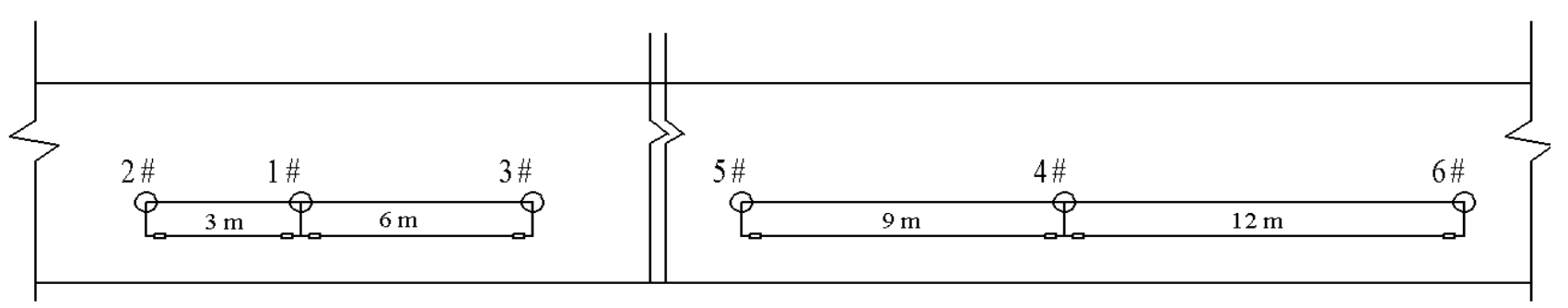

Fig. 2. Layout of drilling holes

Table 1. Layout parameters of the drilling holes

\begin{tabular}{ccccc}
\hline Number & $\begin{array}{c}\text { Drilling hole } \\
\text { diameter/mm }\end{array}$ & Dip angle / & Azimuth/ ${ }^{\circ}$ & $\begin{array}{c}\text { Drilling hole } \\
\text { length/m }\end{array}$ \\
\hline 1\# measure hole & 94 & 30 & 0 & 12 \\
2\# pressure hole & 94 & 30 & 0 & 12 \\
3\# pressure hole & 94 & 30 & 0 & 12 \\
4\# measure hole & 94 & 30 & 0 & 12 \\
5\# pressure hole & 94 & 30 & 0 & 12 \\
6\# pressure hole & 94 & 30 & 0 & 12 \\
\hline
\end{tabular}

The distance between the $1 \#$ measure hole and the $2 \#$ pressure hole is $3 \mathrm{~m}$; the distance between the $1 \#$ measure hole and the $3 \#$ pressure hole is $6 \mathrm{~m}$; the distance between the $4 \#$ measure hole and the $5 \#$ pressure hole is $9 \mathrm{~m}$, and the distance between the $4 \#$ measure hole and the $6 \#$ pressure hole is $12 \mathrm{~m}$. The test steps are described as follows:
First, the 2\#, 3\#, 5\#, and 6\# pressure holes are constructed. Within 24 hours after the construction is finished, the cement mortar is used to seal holes, and the depth of the sealed hole is $12 \mathrm{~m}$.

Second, after cement solidification, the pressure gauge is installed, the joint is ensured to have no leakage, and the gas pressure in every drilling hole is observed every five 
minutes. When the pressure gauge readings have not changed for 3 consecutive days, the pressure is regarded as stable.

Third, after all the pressure gauge readings are stable, construction of the $1 \#$ and $4 \#$ measure holes begins. The hydraulic flushing process is performed, and the gas pressure in every pressure hole is observed and recorded. The hydraulic flushing process cannot stop until the gas pressure drops to $0 \mathrm{MPa}$ or no crushed coal is flushed out from the measure holes.

\subsection{Test results and analysis}

The pressure change curves in four pressure holes in the hydraulic flushing process are shown in Figure 3. When the hydraulic flushing in the $1 \#$ measure hole lasts 30 minutes, the quantity of flushed coal is $2.91 \mathrm{t}$, which is equivalent to expanding the drilling hole with a diameter of $94 \mathrm{~mm}$ into a cavity with a diameter of $759 \mathrm{~mm}$. When the hydraulic flushing process in the $4 \#$ measure hole lasts 45 minutes, the return water is clear and the quantity of flushed coal is 4.11 $\mathrm{t}$, which is equivalent to expanding the drilling hole with a diameter of $94 \mathrm{~mm}$ into a cavity with a diameter of $953 \mathrm{~mm}$.

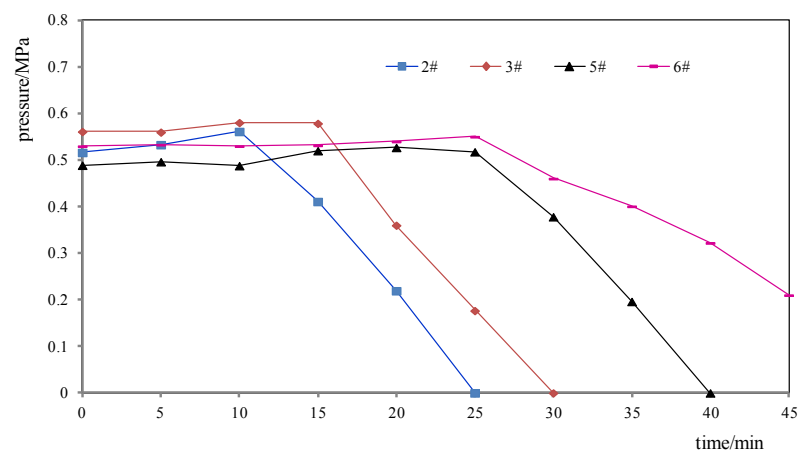

Fig. 3. Pressure change curves in four pressure holes during hydraulic flushing

From Figure 3, we can obtain the following results:

(1) The initial gas pressure of the $2 \#$ pressure hole is $0.52 \mathrm{MPa}$. During hydraulic flushing, the gas pressure increases. When the hydraulic flushing process lasts 10 minutes, the gas pressure reaches the maximum and then decreases gradually. When the hydraulic flushing process lasts approximately 25 minutes, the gas pressure decreases to $0 \mathrm{MPa}$.

(2) The initial gas pressure of the $3 \#$ pressure hole is $0.56 \mathrm{MPa}$. During hydraulic flushing, the gas pressure increases. When the hydraulic flushing process lasts 15 minutes, the gas pressure reaches the maximum of $0.58 \mathrm{MPa}$ and then gradually decreases. When the hydraulic flushing process lasts approximately 30 minutes, the gas pressure decreases to $0 \mathrm{MPa}$.

(3) The initial gas pressure of the $5 \#$ pressure hole is $0.49 \mathrm{MPa}$. During hydraulic flushing, the gas pressure increases. When the hydraulic flushing process lasts 25 minutes, the gas pressure reaches the maximum of $0.53 \mathrm{MPa}$ and then gradually decreases. When the hydraulic flushing process lasts approximately 40 minutes, the gas pressure decreases to $0 \mathrm{MPa}$.

(4) The initial gas pressure of the $6 \#$ pressure hole is $0.52 \mathrm{MPa}$. During hydraulic flushing, the gas pressure increases. When the hydraulic flushing process lasts 10 minutes, the gas pressure reaches the maximum of $0.55 \mathrm{MPa}$ and then gradually decreases. When the hydraulic flushing process lasts approximately 45 minutes, the gas pressure decreases to $0.21 \mathrm{MPa}$ and no crushed coal is flushed out.

The pressure of water jet on coal causes the coal in the flushing zone to generate internal stress, which is mainly manifested by the pressure increase in four pressure holes during hydraulic flushing. With the hydraulic flushing ongoing, when the maximum impact force generated by water jet exceeds the maximum shear strength of coal, the shear failure of the coal appears, the coal stress alters, and the stress gradient around the drilling holes decreases, which causes the pressure in four pressure holes to decrease gradually. The pressures in the $2 \#, 3 \#$, and $5 \#$ pressure holes decrease to $0 \mathrm{MPa}$, which indicates that the distances between these pressure holes and their corresponding measure holes are within the effective influence radius. Within the region, the elastic potential energy of coal is released, and the permeability of the coal seam increases. Thus, gas is desorbed and discharged. When the return water of the $4 \#$ measure hole becomes clear, the pressure in the $6 \#$ pressure hole decreases but not to $0 \mathrm{MPa}$, which indicates that the hydraulic flushing measure has less influence on the coal within 9-12 $\mathrm{m}$. The 6 \# pressure hole is beyond the effective influence region of its corresponding measure hole. Consequently, the effective influence radius of the hydraulic flushing measures is considered to be $9 \mathrm{~m}$.

\section{Analysis on Hydraulic Flushing Technology Parameters}

According to the theoretical analysis and the field test, a high coal output (coal output is calculated by the weight of the flushed coal per unit length) corresponds to a large cavity caused by the hydraulic flushing and a large pressure relief range, which indicates improved hydraulic flushing effect. Consequently, the effective influence radius of the hydraulic flushing measures significantly influences the hydraulic flushing effect. In addition, other parameters influence the hydraulic flushing effect; these parameters include hydraulic pressure, critical breaking coal pressure, effective hydraulic pressure, coal output, flushing time, drilling hole angle, and firmness coefficient. The relationships between hydraulic pressure and coal output, critical breaking coal pressure and firmness coefficient, flushing time and coal output, drilling hole angle and coal output, coal output and effective influence radius, as well as the effect of gas outburst prevention are analyzed based on the field test.

\subsection{Relationship between hydraulic pressure and coal output}

The relationship between hydraulic pressure and coal output during hydraulic flushing is obtained by investigating the coal output under different hydraulic pressures in Yi'an Coal Mine, as shown in Figure 4. The linear fitting equation is given as follows: $y=-0.054 x+1.383, R^{2}=0.023$, where $x$ is the hydraulic pressure, $y$ is the coal output, and $R$ is the coefficient of determination. Apparently, the coal output is not positively correlated with the hydraulic pressure, and the discrete degree is high. Moreover, the coal output has a decreasing trend with the increase of the hydraulic pressure, thereby indicating that if the impact force of water jet can meet the work required in breaking the coal, then the hydraulic pressure will be high and the small nozzle diameter can reduce the target distance and the scope of coal failure. In addition, high-pressure water jet was 


\section{Journal of Engineering Science and Technology Review 8 (4) (2015) 118- 124}

experimentally studied in Leningrad Mining Institute when the nozzle diameter $\mathrm{d}_{0}$ was $3.0-5.3 \mathrm{~mm}$ [23]. The result indicated that the maximum impact force appeared at the section that was 400-500 $\mathrm{d}_{0}$ away from the outlet. Behind the section, the impact force decreased and its reduction rate increased gradually with the increase of the distance between the nozzle and the outlet.

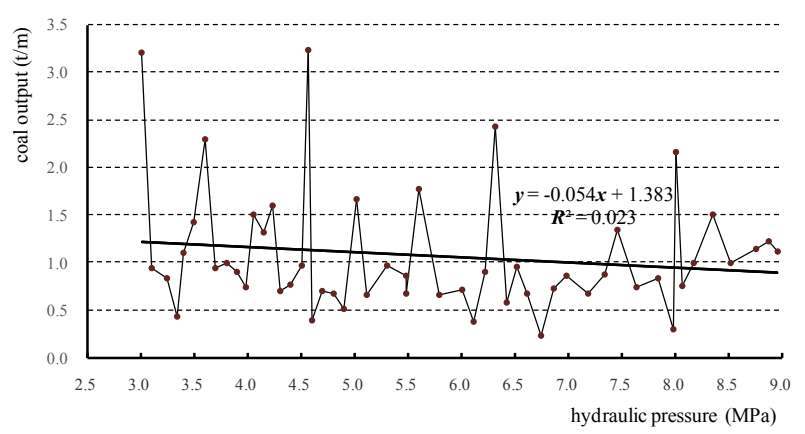

Fig. 4. Relationship between hydraulic pressure and coal output during hydraulic flushing in Yi'an Coal Mine

Therefore, only when the distance between the nozzle and the outlet is within a certain distance can the highpressure water jet break the coal seam and the coal output achieve high efficiency; when the distance between the nozzle and the outlet is greater than this distance, the efficiency of coal output is quite low. Under the premise that the hydraulic pressure generated by the water jet from the nozzle with a small diameter is more than the pressure required to breaking coal, the small hydraulic pressure of water jet is better.

\subsection{Relationship between critical breaking coal pressure and firmness coefficient}

The critical breaking coal pressure was presented in water jet breaking coal theory [24]. Domestic and foreign scholars generally believe that the critical breaking coal pressure is the dynamic pressure on the impact point generated by the water jet, that is, when the water jet impacts the coal wall and the coal begins to break.

During the field test in Yi'an Coal Mine, the pump pressure is generally considered to be the initial pressure. The system pressure loss includes the route loss, the local loss, and water leakage loss. The diameter of the pipeline is mostly 32 or $25 \mathrm{~mm}$, the length is within $200 \mathrm{~m}$, and water leakage places are at the junctions between the shaft and the drill pipe. Therefore, the pressure loss is calculated by twenty percent of the total pressure. The coal firmness coefficient $\mathrm{f}$ in FD003 working face is $0.21-0.27$. The normal flushing pressure is 4-7 MPa, as shown in Figure 4. The coal output is $0.5-3.85 \mathrm{t} / \mathrm{m}$; the critical breaking coal pressure is $3.2-4.5 \mathrm{MPa}$, which is equal to $10-15 \mathrm{f}$. The best breaking coal pressure should be $4.5-6.0 \mathrm{MPa}$, which is equal to $12-20 \mathrm{f}$. According to the above flushing test, the critical breaking coal pressure in Yi'an Coal Mine is about $10 \mathrm{f}$. The best breaking coal pressure is $12-20 \mathrm{f}$.

\subsection{Relationship between flushing time and coal output} According to the dense core hypothesis [25], the coal (rock) is compressed into the dense core by the high-pressure water jet in the beginning. With the hydraulic flushing ongoing, the dense core moves forward and its deformation increases (which is equivalent to putting a rigid wedge into coal). The cracks form in coal (rock) and spread from the impact point to the periphery. Eventually, the coal (rock) is broken. The breaking coal mechanism for hydraulic flushing technology includes the processes of crack formation, water wedge effect, and surface erosion. They occur continuously and alternately, thereby forming the coal breaking process of high-pressure water jet. Therefore, the coal output should increase with the increase of flushing time from a single failure cycle and the flushing process.

The relationship between flushing time and coal output during hydraulic flushing is obtained by investigating the coal output at different flushing times in Yi'an Coal Mine, as shown in Figure 5. The linear fitting equation is given as follows: $y=0.0067 x+1.2517, R^{2}=0.0732$, where $x$ is the flushing time, $y$ is the coal output, and $R$ is the coefficient of determination. Apparently, as the flushing is ongoing, the coal output slightly reduces, which shows that the hydraulic flushing is the process where the coal is peeled off and broken. In addition, Figure 5 shows that the discrete degree between flushing time and coal output is high; therefore, the flushing time is only one of the main factors that influence the flushing effect.

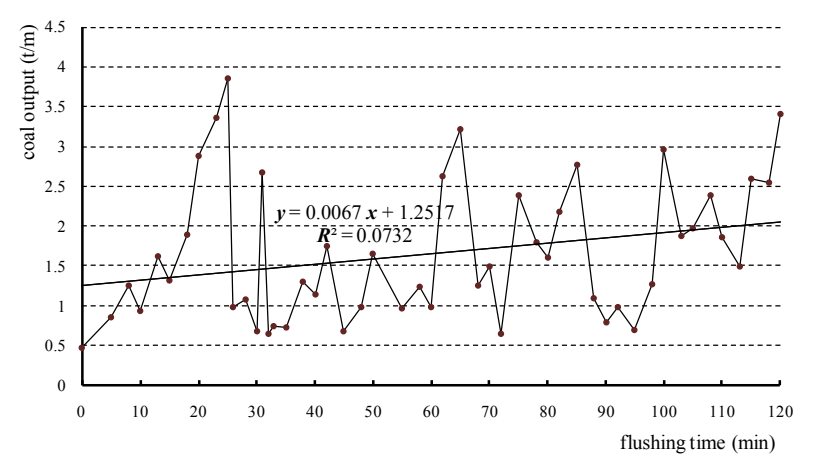

Fig. 5. Relationship between flushing time and coal output

\subsection{Relationship between drilling hole angle and coal output}

The hydraulic flushing measures were performed in the floor roadway of Yi'an Coal Mine; therefore, the drilling holes during hydraulic flushing are upward holes, and the angles of most drilling holes are $30^{\circ}$ to $60^{\circ}$. The relationship between the coal output and the drilling hole angle is obtained by investigation, as shown in Figure 6 . The linear fitting equation is given as follows: $y=-0.0166 x+1.8878$, $R^{2}=0.0413$, where $x$ is the coal output, $y$ is the drilling hole angle, and $R$ is the coefficient of determination. Apparently, the coal output has little relation to the drilling hole angle mainly because after the water jet breaks the coal, the coal output depends mainly on the water quantity, the weight and the discharging powder ability of the drill rod, and the coal breaking resistance. Among them, the water quantity and the discharging powder ability of the drill rod have no relation to the dip angle. The coal breaking resistance mainly depends on the diameter of the drilling hole and the properties of the drill rod. All drilling holes are upward holes; thus, the dip angle is positive, and the weight of the drill rod is beneficial to transporting broken coal. In addition, Figure 6 shows that the discrete degree between the drilling hole angle and the coal output is high; therefore, the drilling hole angle has little influence on the coal output when the drilling hole angle is $30^{\circ}$ to $60^{\circ}$. 
Qing Ye, Geoff G.X. WANG, Zhenzhen Jia, Yi Lu and Yadong Zhang/

Journal of Engineering Science and Technology Review 8 (4) (2015) 118- 124

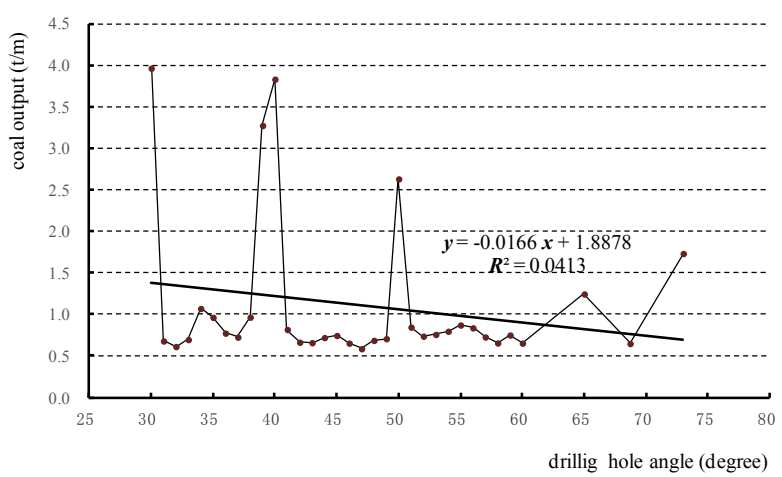

Fig. 6. Relationship between drilling hole angle and coal output

\subsection{Relationship between coal output and effective influence radius}

According to previous field experiences, the coal output during hydraulic flushing is $1 \%$ to $3 \%$ of coal quantity within the region influenced by hydraulic flushing measures. In Yi'an Coal Mine, the length of the drilling field is $29 \mathrm{~m}$ on the tendency, the length is $36 \mathrm{~m}$ on the strike, the coal density is about $1.40 \mathrm{t} / \mathrm{m}^{3}$, the average thickness is $4.5 \mathrm{~m}$, and the coal output is $1 \mathrm{t} / \mathrm{m}$, which meet the above requirements. The relationship between the coal output and the effective influence radius is obtained by investigation, as shown in Figure 7. The linear fitting equation is given as follows: $y=1.2388 x-4.9671, R^{2}=0.5280$, where $x$ is the coal output, $y$ is the effective influence radius, and $R$ is the coefficient of determination. Apparently, the coal output increases with the increase of the effective influence radius, that is, more flushed coal means a greater pressure relief range and the formation of a larger space around the drilling hole. Thus, the effective influence radius is larger. However, this increase is not unlimited because the coal output is also related to the effective breaking coal distance of the highpressure water jet.

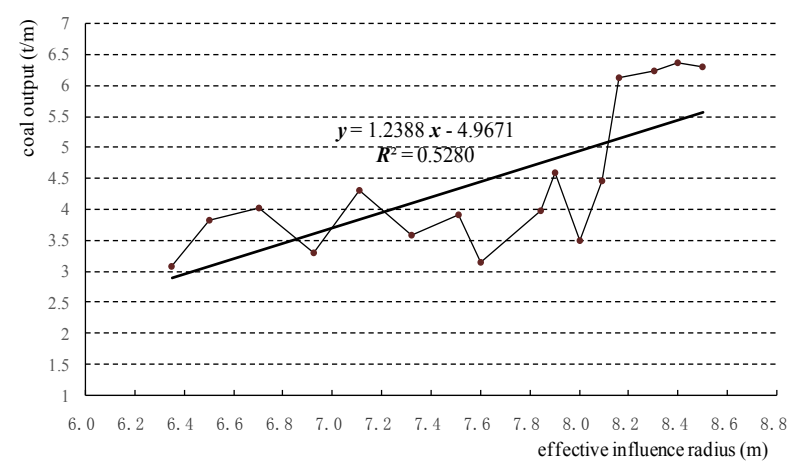

Fig. 7. Relationship between coal output and effective influence radius

\subsection{Analysis on the effect of gas outburst prevention}

After the hydraulic flushing and gas drainage measures were taken, the coal seam was uncovered on August 26, 2012 in Yi'an Coal Mine and the gas outburst forecast was conducted. According to the parameters measured during tunneling, the maximum drilling cutting gas desorption index $\mathrm{h}_{2}$ was $137.2 \mathrm{~Pa}$, the maximum drilling cuttings quantity $\mathrm{S}$ was $2.4 \mathrm{~kg} / \mathrm{m}$, the maximum initial velocity of gas emission from boreholes $\mathrm{q}$ was $3.48 \mathrm{~L} / \mathrm{min}$, gas pressure $\mathrm{P}$ was $0.535 \mathrm{MPa}$, and gas content $\mathrm{W}$ of coal seam was 4.69 $\mathrm{m}^{3} / \mathrm{t}$. According to "Provisions on Prevention and Control of Coal and Gas Outbursts in China," the critical values of the gas outburst forecast in tunneling face are $\mathrm{h}_{2}=200 \mathrm{~Pa}, \mathrm{~S}=6$ $\mathrm{kg} / \mathrm{m}, \mathrm{q}=5 \mathrm{~L} / \mathrm{min}, \mathrm{P}=0.74 \mathrm{MPa}, \mathrm{W}=8 \mathrm{~m}^{3} / \mathrm{t}$. Apparently, the measured values were less than the corresponding critical values, which indicated that after the hydraulic flushing measures were taken, the coal within the influence range of drilling holes had no risk of coal and gas outburst.

\section{Conclusions}

(1) After the hydraulic flushing measures were taken, the quantity of flushed coal from the $1 \#$ and $4 \#$ measure holes were 2.91 and $4.11 \mathrm{t}$, respectively, which was equivalent to expanding the drilling holes with a diameter of $94 \mathrm{~mm}$ into the cavities with diameters of 759 and $953 \mathrm{~mm}$, thereby indicating that the measures could eliminate the coal stress around the drilling hole and fully relieve pressure.

(2) After the hydraulic flushing measures were taken, the pressures in the $2 \#, 3 \#$, and $5 \#$ pressure holes decreased to $0 \mathrm{MPa}$. The pressure in the $6 \#$ pressure hole decreased but did not decrease to $0 \mathrm{MPa}$ when the return water of the $4 \#$ measure hole was clear, which indicated that the hydraulic flushing measures had less influence on the coal within 12 $\mathrm{m}$. The $6 \#$ pressure hole was beyond the effective influence radius of its corresponding measure hole. Consequently, the effective influence radius of the hydraulic flushing measure was considered to be $9 \mathrm{~m}$.

(3) A large distance between the measure hole and the pressure hole corresponds to less influence of hydraulic flushing. Once the distance was beyond the effective influence radius of the corresponding measure hole, the hydraulic flushing measures would have no effect on the coal.

(4) The effect of the hydraulic flushing measures on pressure relief and permeability improvement was evident. Gas pressure and coal stress were reduced. Coal seam permeability increased, and the danger of coal and gas outburst was eliminated.

(5) The technical parameters of hydraulic flushing technology were analyzed. A series of relationships was obtained, including the relationship between hydraulic pressure and coal output, critical breaking coal pressure and firmness coefficient, flushing time and coal output, drilling hole angle and coal output, and coal output and effective influence radius. Furthermore, the effect of gas outburst prevention was analyzed. The research results provide technical support for the optimization of the technical parameters and the test scheme of hydraulic flushing measures.

(6) The process of the hydraulic flushing measures was simple, the construction was safe, and the measures could wet the coal to reduce the dust concentration of the working face during tunneling, as well as improve working conditions.

\section{Acknowledgements}

This work is supported by the National Natural Science Foundation of China (51004048, 51374003) and the Research Projects Human Social Science of the Ministry of Education (13YJA770044). 


\section{References}

1. Yuan, X. P., "The characters and trend of accidents in the coal mining in China". Disaster Advances, 5(4), 2012, pp. 866-869.

2. Cheng, Y. P., Liu, H., Zhang, W., "Status and prevention on countermeasure of coal and gas outburst accidents in China". Coal Science and Technology, 42(6), 2014, pp. 15-18.

3. Lin, B. Q., Zhang, J. G., "Theory and technology of mine gas drainage". China University of Mining and Technology Press, China, Xuzhou, 2007.

4. Ye, Q., Lin, B. Q., "Comprehensive control technologies for extraordinarily high gas emission from fully-mechanized working face". Proceedings of International Mining Forum 2010, 2010, pp. 51-54.

5. Wang, L., Cheng, Y. P., An, F. H., Zhou, H. X., Kong, S. L., Wang, W., "Characteristics of gas disaster in the Huaibei coalfield and its control and development technologies". Natural Hazards, 71(1), 2014, pp. 85-107.

6. He, J., Chen, X. S., "Research state and its development trends for control function of geo logical structure to coal and gas outburst". Journal of Henan Polytechnic University (Natural Science), 28(1), 2009, pp. 1-7.

7. Li, J. X., Lin, B. Q., Li, G. Q., Ye, Q., Xu, S. R., "Theory of pressure relief and permeability increasing for deephole loose blasting and its practice". Safety in Coal Mines, 11(2), 2010, pp. 52-

8. Jia, T. R., Zhang, Z. M., Tang, C. A., Zhang, Y. J., "Numerical simulation of stress-relief effects of protective layer extraction", Archives of Mining Science, 58(2), 2013, pp. 521-540.

9. Liu, M. J., Kong, L. A., Hao, F. C., "Application of hydraulic flushing technology in severe outburst coal". Journal of China Coal Society, 30(4), 2005, pp. 451-454.

10. Wang, X. X., Xia, S. H., Shi, B. M., "Experiment research on hydraulic borehole flushing in No. 13-1 Seam of Pansan Mine". Coal Science and Technology, 39(4), 2011, pp. 60-64.

11. Wang, X. X., Shi, B. M., Mu, C. M., "Study on formation mechanism of gas emission partition in hydraulic flushing coal seam". Journal of China Coal Society, 37(3), 2012, pp. 467-472.

12. Hao, F. C., Sun, L. J., Liu, M. J., "Research on boreholes space optimization of hydraulic flushing considering press relief and gas drainage effect". Journal of Mining and Safety Engineering, 31(5), 2014, pp. 756-763

13. Wang, Z. F., Fan, Y. C., Li. S. S., "Application of borehole hydraulic flushing technology to soft and outburst seam with low permeability". Coal Science and Technology, 40(2), 2012, pp. 5255
14. Wang, K., Li, B., Wei, J. P., Li, P.. "Change regulation of coal seam permeability around hydraulic flushing borehole". Journal of Mining and Safety Engineering, 30(5), 2013, pp. 778-784.

15. Wang, L., Cheng, Y. P., Ge, C. L., Chen, J. X., Li, W., Zhou, H. X., Wang, H. F., "Safety technology for the excavation of coal and gas outburst-prone coal seams in deep shafts". International Journal of Rock Mechanics Mining, 57(1), 2013, pp. 24-33.

16. Chareonsuppanimit, P., Mohammad, S. A., Robinson, R. L. Jr., Gasem, K. A., "High-pressure adsorption of gases on shales: measurements and modeling". International Journal of Coal Geology, 95(6), 2012, pp. 34-46.

17. Cui, X., Bustin, A. M. M., Bustin, R. M., "Measurements of gas permeability and diffusivity of tight reservoir rocks: different approaches and their applications". Geofluids, 9(3), 2009, pp. 208223.

18. Xu, J., Peng, S. J., Zhang, D. D., "Analysis on the effect of gas pressure on coal and gas outburst disaster". Disaster Advances, 3(4), 2010, pp. 442-446.

19. Wang, Y. A., Zhu, Y. H., "The gas prevention and control in coal mine". China Coal Industry Publishing Press, China, Beijing, 2007.

20. Ye, Q., Jia, Z. Z., Lin, B. Q., Li, J. X., Li, G. Q., "Theoretical analysis and practical study on reasonable water pressure of hydrofracturing". Procedia Engineering, 26, 2011, pp. 1361-1369.

21. State administration of production safety supervision and administration, "Direct determination method of gas pressure in coal mine underground (AQ/T 1047-2007)", Coal Industry Press, China, Beijing, 2008

22. State administration of production safety supervision and administration, "Provisions for the prevention of coal and gas outburst". Coal Industry Press, China, Beijing, 2013.

23. Bai, G. J., Zhang, C. R., Jiang, X. G., Liu, Y. W., "Elimination outburst effect and main influencing factors analysis of hydraulic flushing". Journal of Polytechnic University (Natural Science), 29(4), 2010, pp. 440-443.

24. Shen, Z. H., "Theory and technology of water jet". Petroleum University Press, China, Shandong, 1998.

25. Xu, X. D., "Study on the mechanical behavior of the particles in the ultrafine crushing flow field of hydraulic jet". Ph.D Thesis, University of Science \& Technology Beijing, China, Beijing, 2000. 